\title{
Coronary Heart Disease Risk Profile among University of Kwa-Zulu Natal Students
}

\author{
Ellapen, T.J., Essack, F.M., Thwala, S.P., Van Heerden, H.J. \\ University of Kwa-Zulu Natal School of Health Science, Department of Biokinetics, Exercise and Leisure \\ Sciences, Westville Campus, PO Box X54001, Durban, South Africa \\ Correspondence: tellapen1@yahoo.com
}

\begin{abstract}
SUMMARY
Coronary heart disease (CHD) is one of the primary aetiological factors of mortality in many countries. People are no longer as physically active as they were a few decades ago, because of their sedentary lifestyles. This study was conducted to determine the coronary heart disease risk profile of students studying at the Westville campus of the University of Kwa-Zulu Natal (UKZN).

Two hundred and twenty-three students who volunteered participated in the study. Participants underwent a health screening and risk stratification assessment which included an interview (to determine exercise history, and prevalence of hypokinetic diseases), kinanthropometric measures (body mass, stature and skinfold), resting heart rate and blood pressure measures and a bicycle ergometer $\mathrm{PWC}^{170}$ test (indirectly estimate $\mathrm{VO}_{2} \mathrm{max}$ ). Descriptive statistics which included mode, mean, frequency, percentages and inferential statistics comprising chi-square $(p \leq 0.05)$ were employed in the statistical analysis. All participants reported no history of hypokinetic disease and perceived they were not at risk of CHD $(p<0.001)$. The exercise history of males revealed that $\mathbf{8 6 . 6 6 \%}$ participated in exercise, cricket, soccer, rugby and hockey, while $13.34 \%$ were sedentary ( $\mathrm{X}^{2}$ p-value; $\left.1.58 \mathrm{E}-17\right)$. Females (88.64\%) were more physically active participating in netball, hockey, athletics and exercise, whilst $11.36 \%$ were sedentary $\left(\mathrm{X}^{2} \mathrm{p}\right.$-value; 4.2E-13). Active female participants exercised and played sport for 2.38 sessions per week for an average duration of 34.28 minutes per session. The active male participants exercised and played sport for 0.65 sessions per week for an average of 30 minutes per session.

Descriptive statistical analyses identified the female participants' mean BMI $\left(24.34 \mathrm{~kg} / \mathrm{m}^{2}\right)$, percent body fat $(20.72 \%)$, resting heart rate $(78.19 \mathrm{bpm})$, mean arterial pressure $(87.85 \mathrm{mmHg})$ and $\mathrm{V} 0{ }_{2} \mathrm{max}(38.93$ $\mathrm{ml} / \mathrm{kg} / \mathrm{min}$ ) as being within their age and gender norms. Similarly male participants' mean BM I (23.05 kg/m $\left.{ }^{2}\right)$, percent body fat $(12.29 \%)$, resting heart rates $(73.14 \mathrm{bpm}), \mathrm{MAP}(87.75 \mathrm{~mm} \mathrm{Hg})$ and V O ${ }_{2} \mathrm{max}(39.03 \mathrm{ml} / \mathrm{kg} / \mathrm{min})$ complied with their age and gender norms. The study concluded that the participants are not at risk of CHD.
\end{abstract}

KEYWORDS: coronary heart disease, health

\section{INTRODUCTION}

Good health is defined as a state of complete physical and mental well-being (Kent, 2005). Good health requires that an individual utilizes their physical and mental resources to preserve and/or promote their state of well-being (Kent, 2005). Good physical fitness is the most important overall determinant of a population's health (Brukner and Khan, 2006). The primary factors that adversely affect a person's physical health are: (i) physical trauma and repetitive overuse that generally produces musculoskeletal injury and (ii) hypokinetic diseases. Hypokinetic diseases include coronary heart disease, obesity, diabetes mellitus and lower back pain, which are often brought on by insufficient exercise (Kent, 2005). Coronary heart disease (CHD) is one of the primary aetiological factors of mortality in many countries (Soh et al., 2010). Individuals who are physically unfit are at increased risk of CHD and co-morbidities such as hypertension, diabetes mellitus, hypercholesterolaemia, and obesity (Durstine and Moore, 2003). People are no longer as physically active as they were a few decades ago, 
because of their sedentary lifestyle (Deckelbaum and Williams, 2001; Zeelie, Moss and Kruger, 2010). One of the primary factors accounting for this sedentary lifestyle is the increased dependence on modern technology. This decreased physical activity is a contributing factor to the ever-increasing obesity level (Kruger et al., 2005).

It is widely acknowledged that regular physical exercise, especially aerobic exercises, has both cardioprotective and CHD preventative benefits (Shaw, Shaw and Brown, 2009). Epidemiologists have defined CHD risk factors into two categories: modifiable and un-modifiable (ACSM, 2001; Ellapen, 2002). The modifiable risk factors include obesity, unhealthy diet, excessive alcohol consumption, diabetes mellitus, hormonal imbalances and stress levels; while the un-modifiable risk factors are advanced age, gender and genetics (ACSM, 2001; Ellapen, 2002).

The American College of Sports Medicine - ACSM (2001) states that good physical fitness is synonymous with optimal health. An individual's physical fitness index is widely accepted as a non-invasive method of measuring a person's physical health and well-being. Rehabilitation specialists frequently employ pre-participation health screening and risk stratification assessments to determine a patient's initial fitness status and subsequently infer the health profile prior to prescribing an exercise and/or rehabilitative programme (Ellapen et al., 2010). Integrated efficient human physiological functioning results in optimal health that can be maintained through regular physical exercise (McArdle et al., 2007). Pre-participation health screening and risk stratification assessments are frequently used by rehabilitation specialists for clinical insights into the patient's physiological systems functioning and subsequently to determine the patient's CHD risk profile. There is anecdotal opinion (Kruger et al., 2005) that South African adolescents and young adults are in poor physical fitness, inferring poor health. This study investigated the CHD health risk profiles of University of Kwa Zulu Natal (UKZN) students, studying at the Westville campus, South Africa.

\section{METHODOLOGY}

The inclusion criteria for eligibility to participate in the study were that all participants must be registered UKZN's students studying at the Westville campus, and must volunteer and give informed consent. Announcements were posted around the Westville campus inviting voluntary participants from students studying at the campus, Faculty of Health Science, School of Physiotherapy, Sports Science and Optometry. A total of 420 students volunteered, however only 223 qualified to participate, which represented $53.09 \%$. This percentage exceeds the figure required in the statistical rule of thumb pertaining to the minimum percentage of subjects participating in a study, which puts the yielding power of significance of findings at $30 \%$ as suggested by Terre-Blanche et al. (2008).

All participants underwent a Health Screening and Risk Stratification Assessment (HSRSA) intended to determine their fitness and CHD health risk profile. The HSRSA included the completion of a Physical Activity Readiness Questionnaire (PAR-Q), informed consent form, a kinanthropometric assessment, and a bicycle ergometer test aimed to measure cardiovascular efficiency. The HSRSA was conducted by the same rehabilitative specialists (to ensure test-re-test reliability) working at the UKZN's Sports Science Biokinetic Clinic from 09h00 to $11 \mathrm{~h} 30$ daily.

An interview was employed to determine each participant's exercise history, prevalence of hypokinetic disease and regular use of medication. After the interview, resting heart rate and blood pressure were measured and recorded. All participants were seated for five minutes before resting heart rate and blood pressure were measured. Resting heart rate was recorded using the polar heart rate monitor Polar F11. Blood pressure was measured on the left arm using a palm aneroid sphygmomanometer and Sprague-Rappaport stethoscope according to the ACSM Guidelines for Exercise Testing and Prescription (ACSM, 2001). Three readings were taken for each participant by the same rehabilitative specialist (to ensure test-re-test reliability). These resting values were used to compute the participant's resting rate pressure product and mean arterial pressure (MAP). The rate pressure product is the product of systolic blood pressure and heart rate and it is the work index of the myocardium that is responsible to the heart's contractile efficiency (Kitamura, 1972). Mean arterial pressure represents the average force exerted by the blood against the resistance within the arterial vessels within a single cardiac cycle. It is computed as follows:

MAP $=$ diastolic blood pressure $+[0.333$ (systolic blood pressure - diastolic blood pressure)]

At rest, a healthy adult's systolic blood pressure averages $120 \mathrm{mmHg}$ and the diastolic blood pressure is $80 \mathrm{mmHg}$. The heart remains in diastole longer than it does in systole, 
therefore the average or mean arterial pressure (MAP) is slightly less than simply the average of the systolic and diastolic blood pressures (McArdle et al., 2007).

Kinanthropometric assessment involved measuring the participant's body mass, stature, three sites skinfold (employed table from Baumgartner and Jackson, 1995). Body mass index (BMI) was computed by dividing a participant's body mass by their height squared (BMI = $\mathrm{kg} / \mathrm{m}^{2}$ ). The three sites for skinfold measurement for males were: chest, abdomen and mid-thigh, and for females: triceps, supra-iliac and mid-thigh, all on the right side of the body. The sum of the measurements from the three sites was employed to determine the participant's percent body fat, according to the Baumgartner and Jackson percent body fat age matched tables (Baumgartner and Jackson, 1995). The bicycle ergometer physical work ${ }^{170}\left(\mathrm{PWC}^{170}\right)$ test was administered according to the Davies and Daggett protocol (1977) to indirectly determine a participant's oxygen consumption $\left(\mathrm{VO}_{2} \mathrm{max}\right)$. Descriptive statistics of mode, mean, frequency, percentages and inferential statistics; chisquare tests $\left(X^{2}\right)(\mathrm{p} \leq 0.05)$ and Pearson correlations were computed to analyse the data using the Statistical Package for the Social Sciences (SPSS) version 7.0 for Windows.

\section{RESULTS}

The mean age of the participants $(n=223)$ was $21.57 \pm 3.82$ years. Females constituted $39.46 \%$ and males $60.35 \%$ of the cohort. The racial demographic differentiation of the cohort was Indian $(34.52 \%)$, Black $(36.77 \%)$, Coloured $(3.58 \%)$ and White $(25.11 \%)$. The interview revealed that $86.66 \%$ of the male participants engaged in exercise and sports such as cricket, soccer, rugby and hockey, while $13.34 \%$ were sedentary ( $X^{2} p$-value; $\left.1.58 E-17\right)$. Females were slightly more physically active $(88.64 \%)$ participating in netball, hockey, athletics and exercise, while $11.36 \%$ were sedentary ( $X^{2} p$-value; 4.2E-13). Active female participants exercised and participated in sports for 2.38 sessions per week for an average duration of 34.28 minutes per session. The active male participants exercised and participated in sports for 0.65 sessions per week for an average of 30 minutes per session.

Participants reported that they had no history of hypokinetic disease and/or use of medication $(p<0.001)$. All participants reported that they were in good health and not at risk of CHD $(p<0.001)$. The results were categorized into male and female due to anatomical and physiological differences. Female and male participants' rate pressure products (RPP) were 8787.23 and 8579.53 respectively. The female $(78.19 \mathrm{bpm})$ and male $(73.14$ bpm) mean resting heart rates were considered desirable. However, the male $(117.23 \mathrm{mmHg})$ and female $(114.36 \mathrm{mmHg})$ mean systolic blood pressures were within the normative range of $120 \mathrm{mmHg}$ and $115 \mathrm{mmHg}$ respectively.

Table 1. Physical and performance characteristics of the female students $(n=88)$

\begin{tabular}{|c|c|c|c|c|c|}
\hline & Black $(n=35)$ & Indian $(n=18)$ & Colored $(n=2)$ & White $(n=33)$ & Total $(\mathrm{n}=88)$ \\
\hline \multirow[t]{2}{*}{ Age (yrs) } & 20.14 & 22.44 & 22.00 & 21.15 & 21.43 \\
\hline & $(4.31)$ & $(6.77)$ & $(4.24)$ & $(1.73)$ & $(1.01)$ \\
\hline \multirow[t]{2}{*}{ Body mass (kg) } & 60.38 & 58.34 & 52.90 & 60.01 & 57.90 \\
\hline & $(7.79)$ & $(11.25)$ & $(4.10)$ & $(6.89)$ & $(3.45)$ \\
\hline \multirow[t]{2}{*}{ Stature (m) } & 1.59 & 1.56 & 1.60 & 1.62 & 1.59 \\
\hline & $(0.05)$ & $(0.07)$ & $(0.02)$ & $(0.06)$ & $(0.02)$ \\
\hline \multirow[t]{2}{*}{ Body mass index $\left(\mathrm{kg} / \mathrm{m}^{2}\right)$} & 23.93 & 24.20 & 26.51 & 22.74 & 24.34 \\
\hline & $(3.70)$ & $(4.08)$ & $(1.04)$ & $(2.69)$ & $(1.57)$ \\
\hline \multirow[t]{2}{*}{$\%$ body fat } & 23.20 & 26.19 & 12.25 & 21.24 & 20.72 \\
\hline & $(6.19)$ & $(6.49)$ & $(2.61)$ & $(4.80)$ & $(6.00)$ \\
\hline \multirow[t]{2}{*}{ Resting heart rate (bpm) } & 81.05 & 80.83 & 75.00 & 75.80 & 78.19 \\
\hline & (11.99) & $(9.53)$ & $(15.55)$ & $(11.18)$ & $(3.19)$ \\
\hline \multirow[t]{2}{*}{ Mean arterial pressure (MAP) } & 85.24 & 85.56 & 89.56 & 91.05 & 87.85 \\
\hline & $(9.23)$ & $(7.32)$ & $(5.14)$ & $(5.23)$ & $(2.89)$ \\
\hline \multirow[t]{2}{*}{ Rate pressure product (RPP) } & 9262.39 & 9169.35 & 8325.00 & 9010.84 & 8941.89 \\
\hline & $(2304.84)$ & $(2498.05)$ & $(2681.34)$ & $(1414.25)$ & $(2224.62)$ \\
\hline \multirow[t]{2}{*}{$\mathrm{VO}_{2} \max (\mathrm{kg} / \mathrm{ml} / \mathrm{min})$} & 35.69 & 36.96 & 40.29 & 42.78 & 38.93 \\
\hline & $(9.37)$ & $(7.68)$ & $(8.90)$ & $(11.23)$ & $(3.21)$ \\
\hline
\end{tabular}


Table 2. Physical and performance characteristics of the male students $(n=135)$

\begin{tabular}{|c|c|c|c|c|c|}
\hline Age (yrs) & $\begin{array}{l}22.06 \\
(3.15)\end{array}$ & $\begin{array}{l}21.77 \\
(4.00)\end{array}$ & $\begin{array}{l}20.83 \\
(1.47)\end{array}$ & $\begin{array}{l}22.3 \\
(2.89)\end{array}$ & $\begin{array}{l}21.74 \\
(0.64)\end{array}$ \\
\hline Body mass $(\mathrm{kg})$ & $\begin{array}{l}72.81 \\
(11.50)\end{array}$ & $\begin{array}{c}70.94 \\
(18.56)\end{array}$ & $\begin{array}{l}69.46 \\
(11.39)\end{array}$ & $\begin{array}{l}71.43 \\
(6.26)\end{array}$ & $\begin{array}{l}71.16 \\
(1.38)\end{array}$ \\
\hline Stature $(\mathrm{m})$ & $1.74(0.07)$ & $1.73(0.08)$ & $1.77(0.06)$ & $1.75(0.07)$ & $1.74(0.01)$ \\
\hline Body mass index $\left(\mathrm{kg} / \mathrm{m}^{2}\right)$ & $\begin{array}{l}23.99 \\
(3.89)\end{array}$ & $\begin{array}{l}23.09 \\
(4.76)\end{array}$ & $\begin{array}{l}21.94 \\
(3.44)\end{array}$ & $\begin{array}{l}23.21 \\
(2.42)\end{array}$ & $23.05(0.84)$ \\
\hline$\%$ body fat & $13.4(7.03)$ & $13.75(6.56)$ & $10.85(5.26)$ & $11.17(3.80)$ & $12.29(1.49)$ \\
\hline Resting heart rate (bpm) & $\begin{array}{l}74.38 \\
(11.04)\end{array}$ & $\begin{array}{l}76.71 \\
(9.63)\end{array}$ & $\begin{array}{l}68.33 \\
(8.04)\end{array}$ & $\begin{array}{c}73.17 \\
(10.04)\end{array}$ & $\begin{array}{l}73.14 \\
(3.53)\end{array}$ \\
\hline $\begin{array}{l}\text { Mean arterial pressure } \\
\text { (M AP) }\end{array}$ & $\begin{array}{l}89.54 \\
(5.78)\end{array}$ & $\begin{array}{l}87.25 \\
(7.98)\end{array}$ & $\begin{array}{l}85.85 \\
(8.61)\end{array}$ & $\begin{array}{l}88.39 \\
(6.55)\end{array}$ & $\begin{array}{l}87.75 \\
(1.57)\end{array}$ \\
\hline $\begin{array}{l}\text { Rate pressure product } \\
\text { (RPP) }\end{array}$ & $\begin{array}{c}8904.27 \\
(1863.40)\end{array}$ & $\begin{array}{l}8900.66 \\
(1360.26)\end{array}$ & $\begin{array}{c}7880.49 \\
(1520.26)\end{array}$ & $\begin{array}{c}8612.84 \\
(1557.78)\end{array}$ & $\begin{array}{c}8574.69 \\
(1575.42)\end{array}$ \\
\hline $\mathrm{VO}_{2} \max (\mathrm{kg} / \mathrm{ml} / \mathrm{min})$ & $\begin{array}{l}40.46 \\
(7.82)\end{array}$ & $\begin{array}{l}35.93 \\
(8.25)\end{array}$ & $\begin{array}{l}38.33 \\
(9.41)\end{array}$ & $\begin{array}{l}41.40 \\
(9.14)\end{array}$ & $\begin{array}{l}39.03 \\
(2.43)\end{array}$ \\
\hline
\end{tabular}

\section{DISCUSSION}

A high portion of the male and female students participated in sports and exercise; however they did not meet the minimum criteria prescribed by the American Heart Association (AHA) of 30 minutes of exercises, three sessions per week (AHA, 2003). This finding concurs with the findings of Kruger et al. (2005) and Zeelie et al. (2010), which state that adolescents and young adults (with similar age strata as the present study) are living sedentary lifestyles. Morris et al. (1966) report that a sedentary lifestyle increases the risk of diabetes mellitus, hypertension, obesity and dyslipidemia, all of which are comorbidities of CHD. The small sample size of the active and sedentary participants in this study will make statistical comparison between their physical and performance characteristics unreliable.

Body mass index is an elementary mathematical equation commonly used to describe people's body composition (Kent, 2005). The American College of Sports Medicine (2001) considers a person with a BMI less than $19.99 \mathrm{~kg} / \mathrm{m}^{2}$ as underweight, $20.0-24.99 \mathrm{~kg} / \mathrm{m}^{2}$ as healthy, $25.0-29.99 \mathrm{~kg} / \mathrm{m}^{2}$ as overweight, and above $29.99 \mathrm{~kg} / \mathrm{m}^{2}$ as obese. The BMI of the female and male participants fell within the healthy category, $20.0-24.99 \mathrm{~kg} / \mathrm{m}^{2}$ (ACSM, 2001). However the coloured female students' mean BMI was above the accepted normative range for healthy individuals. A critical limitation of the use of BMI is its generalized description of individuals' body composition.
Due to this inherent limitation of BMI, specific anatomical skinfold sites were measured to derive the participants percent body fat. The female and male participants' mean percent body fat were $20.72 \%$ and $12.29 \%$ respectively (which falls within the age and gender normative ranges). The coloured female students' mean percent body fat was $12.25 \%$ suggesting that they have a high percent of fat free mass. However the percent body fat of Indian female students who had acceptable BMI was greater $\left(24.20 \mathrm{~kg} / \mathrm{m}^{2}\right)$ than the accepted normative range. McArdle et al. (2007) proposed that percent body fat ranging from $15-20 \%$ for males and $18-25 \%$ for females is considered healthy, 20-29\% for males and $26-30 \%$ for females as overweight, and beyond $30 \%$ for both genders as obese. Shaw et al. (2009) report that regular physical exercise, especially aerobic exercises, have both cardioprotective and CHD preventive benefits. McArdle et al. (2007) postulated that people with high percent body fat place tremendous strain on their muscles to carry them from place to place, thereby producing an increased risk of muscle over-use injury. The impact of muscle over-use in overweight and obese individuals critically increases the risk of cardiac arrest (ACSM, 2001; McArdle et al., 2007).

College students aged 18-22 years old have average $\mathrm{VO}_{2} \mathrm{max}$ values ranging from $38-42 \mathrm{ml} / \mathrm{kg} / \mathrm{min}$ (females) and $44-50 \mathrm{ml} / \mathrm{kg} / \mathrm{min}$ (males) (Wilmore et al., 2007). Higher $\mathrm{VO}_{2} \max$ values indicate cardiovascular efficiency, which arrests the onset of CHD. The male participants in 
this study had an estimated mean $\mathrm{VO}_{2}$ max value far below $(39.03 \mathrm{ml} / \mathrm{kg} / \mathrm{min})$ the normative values, whilst the female participants had estimated mean $\mathrm{VO}_{2}$ max values within the accepted norm $(38.93 \mathrm{ml} / \mathrm{kg} / \mathrm{min})$.

The resting cardiovascular measures, heart rate and blood pressure provide clinical insight into the health and efficiency of the cardiovascular system. Wilmore et al. (2007) stated that a resting heart rate of $72 \mathrm{bpm}$ is considered healthy. Individuals with resting values higher than $100 \mathrm{bpm}$ (tachycardia) are at high risk of cardiac arrest. On the other hand, people with heart rates below 60 bpm (bradycardia) are considered very fit and exhibit low risk of cardiac arrest (Kent, 2005; McArdle et al., 2007). However, the general rule of thumb is that the lower the resting heart rate the fitter and healthier the person, and the less the risk profile of CHD (McArdle et al., 2007). The mean resting heart rates (RHR) of the male participants $(n=135)$ were within the range of $65-75 \mathrm{bpm}$ indicating efficient chronotropic function, while the rates for female students were slightly higher than the accepted normative range. Further statistical analyses indicate that the mean RHR for all students was higher than the accepted normative range, which imposes a greater myocardial workload at rest.

Epidemiologists agree that a resting rate pressure product that is continuously maintained above 6000 overworks the heart muscles, increasing the risk of developing CHD and subsequent cardiac arrest (Hagberg, 1983). The rate pressure products of female and male participants in this study were above the aforementioned norm (Hagberg, 1983). The mean resting heart rates were considered desirable as they were within the normative range of 7280bpm (McArdle et al., 2007). Similarly the male and female students' mean systolic blood pressures were within the normative range of $120 \mathrm{mmHg}$ and $115 \mathrm{mmHg}$ respectively (Durstine and Moore, 2003). The Indian students' RRP, percent body fat and RHR were above the respective normative values which increase the suspicion of higher myocardial demand at rest. It is recommended that further investigations be conducted to determine the clinical cardiac risk profile of UKZN's students. However, participants' MAP values' fell within the normative range, indicating limited resistance to blood flow in the arteries (Paffenbarger, 1993; Gutin, 1996). The normative MAP value is $93.3 \mathrm{mmHg}$ (Mann, 1965).

\section{CONCLUSION}

Judging by the results of this pilot study, it could be concluded that the female and male students of UKZN were not at risk of CHD. This study was only conducted at one of the five campuses of the University of Kwa-Zulu Natal. Future studies should however be undertaken to document CHD risk factors in a larger cohort of UKZN students from the five campuses. This information will add value to the limited body of knowledge on CHD surveillance studies among South African tertiary students.

\section{ACKNOWLEDGEMENTS}

The authors would like to extend their appreciation and gratitude to Mrs. N. Ellapen, for her assistance during the study.

\section{References}

American College of Sports Medicine (ACSM) (2001). ACSM's Guidelines for Exercise Testing and Prescription. Philadelphia: Lippincott, Williams \& Wilkins.

American Heart Association (AHA) (2003). Heart Disease and Stroke Statistics update. American Heart Association, Dallas.

Baumgartner, T.A. and Jackson, A.S. (1995). Measurement for Evaluation $\left(5^{\text {th }}\right.$ ed.) Times Mirror Higher Education Group, Inc. Dubuque, Iowa.

Brukner, P. and Khan, K. (2006). Clinical Sports Medicine ( $3^{r d}$ ed.). New York: The McGraw Hill Company.

Davies, B. and Daggett, A. (1977). Responses of adult women to programmed exercises. British Journal of Sports Medicine 11(3): 122-126.

Deckelbaum, R.J. and Williams, C.L. (2001). Childhood obesity: The health Issue. Obesity Research 9(4): 2398-2438.

Durstine, J.L. and Moore, G.E. (2003). ACSM's Exercise Management for Persons with Chronic Diseases and Disabilities. New York: Human Kinetics.

Ellapen, T.J. (2002). Effects of Exercise on the Aged. Unpublished thesis. University of Durban Westville.

Ellapen, T.J., Abrahams, S., Desai, F.A., Narsigan, S., Mortimer, J., Rugbeer, N., Pillay, K. and van Herdeen, H.J. (2010). A profile of biokinetic services provided by the University of Kwa-Zulu Natal, 2005-2009. African Journal of Physical Education, Recreation and Dance 16(4): 560-569.

Gutin, B. (1996). Physical training, lifestyle, education and coronary risk factors in obese girls. Medicine and Science in Sport and Exercise 28: 19.

Hagberg, J.M. (1983). Effects of 12 months of intense exercise training on stroke volume in patients with coronary artery disease. Circulation 67: 1194. 
Kent, M. (2005). Oxford Dictionary of Sports Science and Medicine. Oxford: University Press.

Kitamura, K. (1972). Hemodynamic correlates of myocardial oxygen consumption during upright exercises. Journal of Applied Physiology 32: 516.

Kruger, H.S., Puoane, T., Senekal, M. and Van Der Merwe, M.T. (2005). Obesity in South Africa: Challenges for government and health professionals. Public Health Nutrition 8: 491-500.

Mann, G.V. (1965). Physical fitness and immunity to heart disease in Masai. Lancet 2: 1308.

McArdle, W.D., Katch, F.I. and Katch, V.L. (2007). Exercise Physiology (6 $6^{\text {th }}$ ed.). Baltimore: Lippincott, Williams \& Wilkins, Philadelphia.

Morris, J.N., Kagan, A., Pattison, D.C. and Gardner, M.J. (1966). Incidence and prediction of ischemic heart disease in London busmen. Lancet 2 (7463): 533-559.

Paffenbarger, R.S. (1993). The association between changes in physical activity level and other lifestyle characteristics with mortality among men. North England Journal of Medicine 328: 538.
Shaw, I., Shaw, B. and Brown, G.A. (2009). Influence of strength training on cardiac risk prevention in individuals without cardiovascular disease. African Journal of Physical Education, Recreation and Dance 15(3): 424-432.

Soh, K.G., Soh, K.L., Sofian, Y., Ong, L.S. and Ruby, H. (2010). Association between fatness and coronary heart disease risk factors in adolescents. African Journal of Physical Education, Recreation and Dance 16(4): 526-534.

Terre-Blanche, M., Durrheim, K. and Painter, D. (2008). Research in Practice. Cape Town: University of Cape Town Press: 50.

Wilmore, J.H., Costill, D.L. and Kenney, W.L. (2007). Physiology of Sport and Exercise ( $9^{\text {th }}$ ed.). Human Kinetics: New York.

Zeelie, A., Moss, S.J. and Kruger, H.S. (2010). The influence of physical activity on components of metabolic syndrome and vascular function in adolescents: a narrative review. African Journal of Physical Education, Recreation and Dance 16(2): 288-300. 